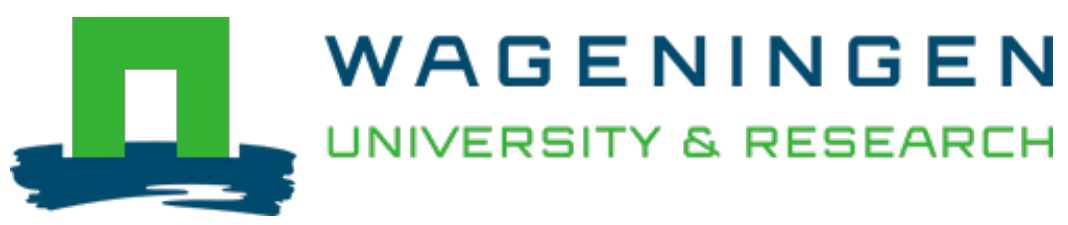

\title{
Understanding the role of oat $\beta$-glucan in oat-based dough systems
}

\author{
Journal of Cereal Science
}

Londono, D.M.; Gilissen, L.J.W.J.; Visser, R.G.F.; Smulders, M.J.M.; Hamer, R.J.

https://doi.org/10.1016/j.jcs.2014.12.003

This article is made publicly available in the institutional repository of Wageningen University and Research, under the terms of article $25 \mathrm{fa}$ of the Dutch Copyright Act, also known as the Amendment Taverne. This has been done with explicit consent by the author.

Article $25 \mathrm{fa}$ states that the author of a short scientific work funded either wholly or partially by Dutch public funds is entitled to make that work publicly available for no consideration following a reasonable period of time after the work was first published, provided that clear reference is made to the source of the first publication of the work.

This publication is distributed under The Association of Universities in the Netherlands (VSNU) 'Article $25 \mathrm{fa}$

implementation' project. In this project research outputs of researchers employed by Dutch Universities that comply with the legal requirements of Article $25 \mathrm{fa}$ of the Dutch Copyright Act are distributed online and free of cost or other barriers in institutional repositories. Research outputs are distributed six months after their first online publication in the original published version and with proper attribution to the source of the original publication.

You are permitted to download and use the publication for personal purposes. All rights remain with the author(s) and / or copyright owner(s) of this work. Any use of the publication or parts of it other than authorised under article $25 \mathrm{fa}$ of the Dutch Copyright act is prohibited. Wageningen University \& Research and the author(s) of this publication shall not be held responsible or liable for any damages resulting from your (re)use of this publication.

For questions regarding the public availability of this article please contact openscience.library@wur.nl 


\title{
Understanding the role of oat $\beta$-glucan in oat-based dough systems
}

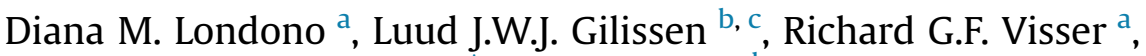

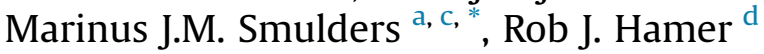 \\ ${ }^{a}$ Wageningen UR Plant Breeding, P. O. Box 386, NL-6700 AJ Wageningen, The Netherlands \\ ${ }^{\mathrm{b}}$ Plant Research International, Wageningen UR, P.O. Box 16, NL-6700 AA Wageningen, The Netherlands \\ ${ }^{c}$ Allergy Consortium Wageningen, P.O. Box 16, NL-6700 AA Wageningen, The Netherlands \\ d Wageningen UR Food Chemistry, P. O. Box 8129, NL-6700 EV Wageningen, The Netherlands
}

\section{A R T I C L E I N F O}

Article history:

Received 19 January 2014

Received in revised form

1 November 2014

Accepted 13 December 2014

Available online 3 January 2015

Keywords:

Oat flour

Oat bread

Avena

Gluten-free bread

\begin{abstract}
A B S T R A C T
B-glucan is one of the components that differentiate oats from other cereals and that contribute to the health-related value of oats. However, so far oats cannot easily be applied in bread-like products without loss of product quality. Here we have studied how the content and viscosity of oat $\beta$-glucan affect the technological properties of oat dough in both a gluten-free and a gluten-containing system. In both systems, increasing the $\beta$-glucan concentration resulted in an increase of dough stiffness and in a reduction of dough extensibility. $\beta$-glucan negatively impacted the elastic properties that additional wheat gluten conferred to oat dough. This effect was smaller for medium-viscosity $\beta$-glucan than for high-viscosity $\beta$-glucan. Interestingly, dough made from low $\beta$-glucan flour $(<2 \%)$ had increased gas retention capacity. Overall, the impact of $\beta$-glucan on the properties of oat dough systems was governed by concentration and viscosity, with or without additional wheat gluten. Our findings indicate that $\beta$ glucan is a key component that determines the rheology of oat-based dough systems and, with that, the technological functionality of oat in dough systems.
\end{abstract}

(c) 2015 Elsevier Ltd. All rights reserved.

\section{Introduction}

Oat constitutes a healthy basis for food products. Oat has gained relevance in human nutrition because it is one of the few cereals with a high content of soluble fibre -namely $\beta$-glucan-, and is a good source of proteins, vitamins, and minerals (Butt et al., 2008). Oat consumption enriches the nutritional quality of the diet, especially of those that suffer from celiac disease (Butt et al., 2008; Londono et al., 2013; Pulido et al., 2009), a chronic inflammatory disorder of the small intestine produced by ingestion of gluten proteins. People suffering from celiac disease have to follow a gluten-free diet. This diet often provides insufficient nutrients and fibres because gluten-free (GF) bakery products are commonly based on starches that have a lower nutritional quality than their cereal counterparts that include gluten (Thompson, 2000).

\footnotetext{
* Corresponding author. Wageningen UR Plant Breeding, P.O. Box 386, NL-6700 A] Wageningen, The Netherlands. Tel.: +31 317480840.

E-mail addresses: dianalondono7@hotmail.com (D.M. Londono), luud.gilissen@ wur.nl (L.J.W.J. Gilissen), richard.visser@wur.nl (R.G.F. Visser), rene.smulders@wur. nl (M.J.M. Smulders), rob.hamer@wur.nl (R.J. Hamer).
}

B-glucans are polysaccharides composed of $\beta-(1 \rightarrow 4)$-linked glucose units separated every two to three units by a single $\beta$ $(1 \rightarrow 3$ )-linked glucose (Bell et al., 1999). Oat $\beta$-glucan is a very interesting component because it helps to reduce cholesterol and post prandial glucose (PPG) levels in blood (Othman et al., 2011). High cholesterol and PPG levels are considered important risk factors for coronary heart disease and diabetes type II respectively (Mathews, 2011; Othman et al., 2011). The positive physiological effect of oat $\beta$-glucan has been attributed to the increased viscosity $\beta$-glucan confers in the intestine, which slows down the intestinal transit and the absorption of sterols and glucose (Anderson and Chen, 1986). Because of that, the American Food and Drug Administration (FDA, 1997) and the European Food Safety Authority (EFSA, 2010) granted a health claim about oat $\beta$-glucan. The recommended intake is $3 \mathrm{~g} /$ day (FDA, 1997).

Oat $\beta$-glucan is used as a functional food ingredient, but can also be used to enhance viscoelastic properties of GF bread formulations (Lazaridou and Biliaderis, 2007). Rheological studies of $\beta$-glucan extracted from different oat varieties showed a positive correlation between total $\beta$-glucan content and water viscosity. The highest viscosity was obtained from oat lines with the highest molecular weight $\beta$-glucan (Colleoni-Sirghie et al., 2003). 
Oats are used mainly as flakes, porridges and as a component of breakfast cereals. Applications that require more processing, such as bread-making, have been explored, but knowledge on the technological properties of oat flour/meal is scarce. This limits product innovation such as the development of breads that comply with consumer standards regarding volume, structure and texture.

The potential of oats for GF bread applications has been studied in formulations based on batter systems (Hüttner et al., 2010). Recently Londono et al. (2014) developed a standard dough system using gluten in the formulation, resulting in a dough system with similar rheological characteristics as wheat dough with respect to its extensibility properties. Differences among oat varieties regarding bread-making potential have been reported for batter as well as dough systems (Hüttner et al., 2011; Londono et al., 2014). In this paper, we aim to understand how $\beta$-glucan content and viscosity affect the extensibility properties of oat dough both in a gluten-free and in a gluten-containing system. The results from this comparative study will help to better manage the technological properties of oat flour, and to determine whether oat varieties with high $\beta$-glucan content, which are preferred for health purposes, are compatible with bread making applications.

\section{Materials and methods}

\subsection{Materials}

The materials used were commercial oat meal (De Vlijt, Wageningen, the Netherlands), vital gluten (provided by Cargill, the Netherlands), and oat $\beta$-glucan of high and medium-viscosity (Megazyme, lots 86608 c and 31205a, respectively). The purity of the $\beta$-glucan extracts was more than $94 \%$, and the average molecular weights were $361 \mathrm{Kd}$ for the high-viscosity and $272 \mathrm{Kd}$ for the medium-viscosity samples.

\subsection{Flour mixtures}

The oat meal was sieved using a series of sieves of 0.500, 0.300, 0.250 mesh. Sieving was done to eliminate bran particles, which can have detrimental effects on dough rheology (Noort et al., 2010). The sieved fine fraction of oat meal $(<0.250 \mathrm{~mm}$ diameter $)$ is what we refer to as 'oat flour' in this study. This flour contained $16 \%$ moisture, $8.7 \%$ protein, $1.2 \% \beta$-glucan, and $72 \%$ starch. Since the major proportion ( $80 \%)$ of the $\beta$-glucan was present in the bran, the sieved flour was substantially lower in $\beta$-glucan. This enabled us to study the effect of a wide range of $\beta$-glucan concentrations by adding the $\beta$-glucan.

We performed two types of experiments to study the effect of $\beta$ glucan on dough properties: the first type was based on a standard dough system containing $12.8 \%$ gluten, developed by Londono et al. (2014). The extensibility properties of this system are similar to those of a weak wheat flour. In the other type of experiment, gluten was excluded from the system. We prepared flour mixtures using oat flour (1.2\% $\beta$-glucan) and we added $\beta$-glucan of high and medium-viscosity to test both the effect of $\beta$-glucan content and the effect of its viscosity properties on dough extensibility. In the gluten-containing system the $\beta$-glucan concentration was increased to 2 and $5 \%$, by adding 0.8 and $3.8 \%$ of $\beta$-glucan, respectively. In the gluten-free system, the concentration was increased to $5 \%$ only.

In order to further demonstrate the effect of $\beta$-glucan, we designed an experiment in which $\beta$-glucan was enzymatically degraded by endo- and exo-glucanase (Megazyme, Lots 91102a and 91101, respectively) as follows. Prior to the experiment, a glucanase solution was prepared by dissolving $60 \mu \mathrm{L}$ endo- and $60 \mu \mathrm{L}$ exoglucanase in $20 \mathrm{~mL}$ distilled water. This solution was used to treat the dough mixture containing $5 \% \beta$-glucan of high-viscosity. An overview of the experimental conditions is presented in Table 1.

\subsection{Dough preparation and extensibility test}

Dough was prepared with a Micro-Farinograph (Brabender instruments, Mod.-No. 8110, Germany), using a $10 \mathrm{~g}$ mixer head. Water was added to prepare a dough system containing gluten with a consistency of $850 \pm 20$ Brabender units (BU) or a gluten-free system with a consistency of $650 \pm 20 \mathrm{BU}$. The reason for the difference in consistency is that flours containing gluten and extra $\beta$ glucan were very sticky and difficult to handle at consistencies $<850 \mathrm{BU}$. The dough was mixed until the consistency reached the peak level in the gluten-containing system (from two to five minutes), or until the consistency became stable in the gluten-free system (from 2.5 to $10 \mathrm{~min}$ ). The mixing time depended on the experimental conditions because the process of hydration to reach the desired consistency was slower for flours with high $\beta$-glucan content and also for the commercial oat meal. Each system, with and without gluten, was compared to its respective control at the same consistency.

After mixing, the dough was allowed to relax in a sealed plastic container within an incubator for $20 \mathrm{~min}$ at $30^{\circ} \mathrm{C}$ and $85 \%$ relative humidity. Then, the complete dough was moulded into a ball by hand (Fig. 1) and pressed between two oiled lubricated and grooved Teflon blocks to make dough strips. The strips were allowed to relax again for 40 min within the mould in a plastic container at $24{ }^{\circ} \mathrm{C}$ and $80 \%$ relative humidity. Subsequently, the dough strip was placed in its holder and maximum resistance to extension $(\mathrm{g})$, extensibility at maximum resistance $(\mathrm{mm})$ and total extensibility $(\mathrm{mm})$ of each strip were measured using a Texture Analyser fitted

Table 1

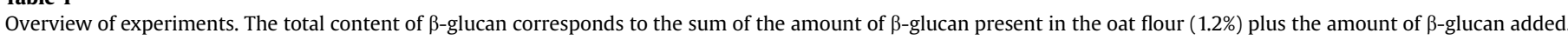

\begin{tabular}{|c|c|c|c|c|c|c|c|c|}
\hline System & Flour type & Oat meal \% & Oat flour \% & $\begin{array}{l}\text { Addition } \\
\beta \text {-glucan } \mathrm{HV}^{\mathrm{a}} \%\end{array}$ & Addition $\beta$-glucan $\mathrm{MV}^{\mathrm{b}} \%$ & $\begin{array}{l}\text { Total } \beta \text {-glucan } \\
\text { concentration \% }\end{array}$ & Gluten \% & Total $^{\mathrm{C}} \%$ \\
\hline \multirow[t]{6}{*}{ With gluten } & Oat meal & 87.2 & - & - & - & 5.5 & 12.8 & 100 \\
\hline & Oat flour (control) & - & 87.2 & - & - & 1.2 & 12.8 & 100 \\
\hline & Oat flour $+0.8 \% \mathrm{HV}$ & - & 86.4 & 0.8 & - & 2.0 & 12.8 & 100 \\
\hline & Oat flour $+0.8 \% \mathrm{MV}$ & - & 86.4 & - & 0.8 & 2.0 & 12.8 & 100 \\
\hline & Oat flour $+3.8 \% \mathrm{HV}$ & - & 83.4 & 3.8 & - & 5.0 & 12.8 & 100 \\
\hline & Oat flour $+3.8 \% \mathrm{MV}$ & - & 83.4 & - & 3.8 & 5.0 & 12.8 & 100 \\
\hline \multirow[t]{4}{*}{ Gluten-free } & Oat meal & 100 & - & - & - & 5.5 & - & 100 \\
\hline & Oat flour (control) & - & 100 & - & - & 1.2 & - & 100 \\
\hline & Oat flour $+3.8 \% \mathrm{HV}$ & - & 96.2 & 3.8 & - & 5.0 & - & 100 \\
\hline & Oat flour $+3.8 \% \mathrm{MV}$ & - & 96.2 & - & 3.8 & 5.0 & - & 100 \\
\hline
\end{tabular}

\footnotetext{
${ }^{\text {a }} \mathrm{HV}$ : Refers to high-viscosity $\beta$-glucans.

b MV: Refers to medium-viscosity $\beta$-glucans.

c $\mathrm{NaCl}(2 \%)$ was added to all mixtures (Method 54-21, AACC).
} 

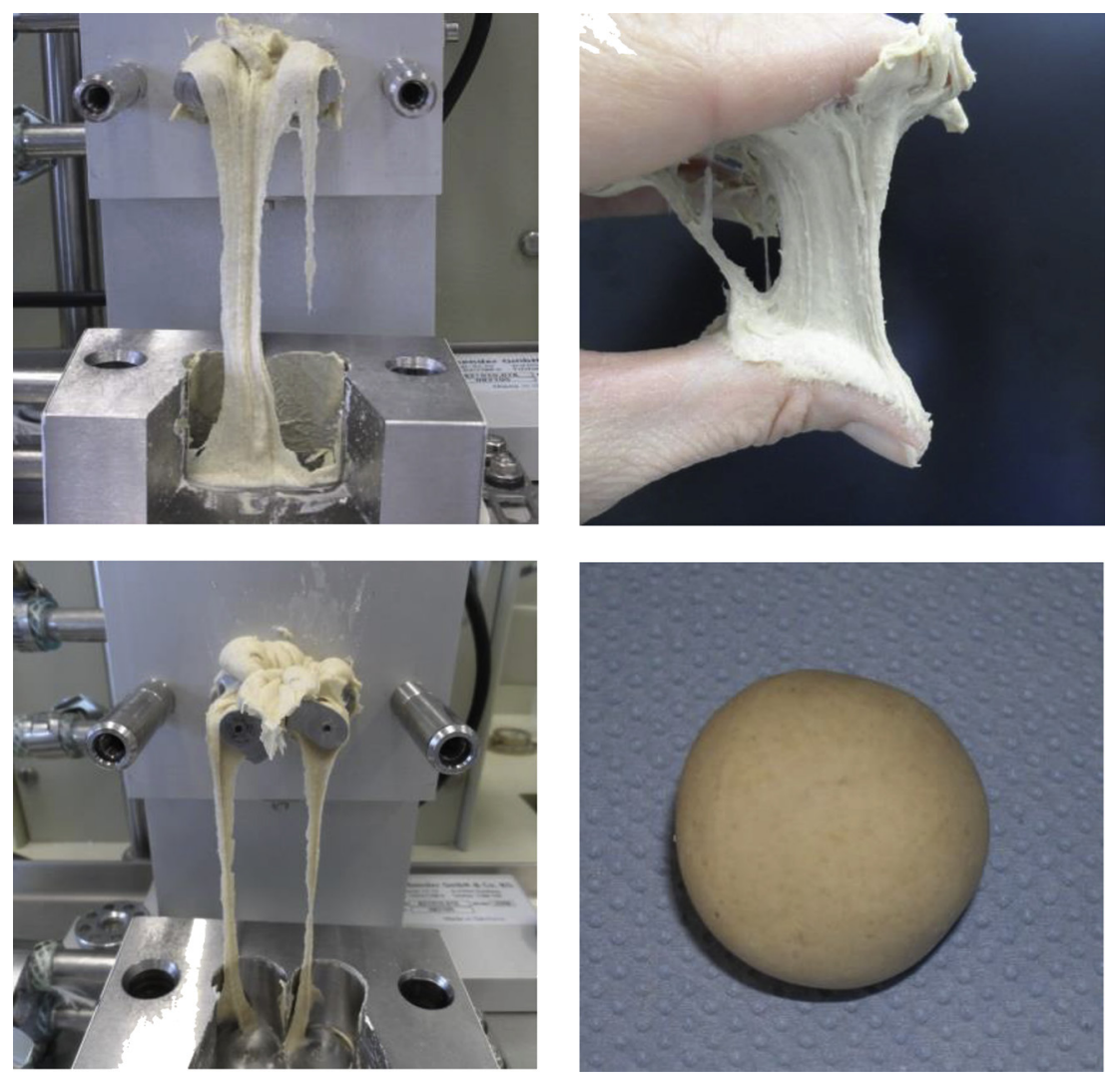

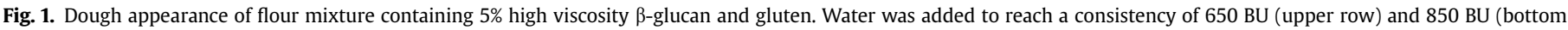
row). It was impossible to manipulate the dough at $650 \mathrm{BU}$ in the presence of gluten, and even at 850 BU the system was very sensitive to over-mixing.

with the SMS/Kieffer Extensibility Rig (Stable Micro systems). The standard settings for wheat flour dough were used according to instructions of the manufacturer. The test was performed in triplicate and 7-9 measurements were taken per dough sample. The resulting graphs represent the average of 21-27 measurements.

\subsection{Gas retention test}

To evaluate the gas-holding capacity of the dough, $1.8 \%$ of dried active bakery yeast (Bruggeman Instant, Belgium, Lot 50109T2) and $1.0 \%$ D-glucose (Sigma) were added to the flour mixtures. The dough was prepared in the Farinograph using the conditions described above and placed in the system described by Peighambardoust et al. (2010) to measure the gas production of a piece of dough $(5 \mathrm{~g})$. The volume of the dough was measured immediately after mixing and again after $20 \mathrm{~mL}$ of gas production. A calibrated cylinder filled with $50 \mathrm{~mL}$ of n-hexane (Sigma) was used to measure the volume displaced by the dough. Five samples per dough mixture were tested and results were averaged to calculate specific volume increase of the dough between mixing and after the production of $20 \mathrm{~mL}$ gas.

\section{Results}

\subsection{Effect of oat $\beta$-glucan in a gluten-containing oat-based dough system}

The effect of high and medium-viscosity $\beta$-glucan in a glutencontaining oat flour dough system was determined at concentrations of $1.2,2$ and $5 \% \beta$-glucan (Table 1 ). These concentrations were obtained by adding 0.8 and $3.8 \% \beta$-glucan to the oat flour described, which already contained $1.2 \% \beta$-glucan and was used as control. The dough was prepared at $850 \pm 20$ BU consistency because at lower consistencies, the system was very sticky and became impossible to handle when extra $\beta$-glucan was added (compare dough at $650 \mathrm{BU}$ in the upper two panels of Fig. 1 with dough at $850 \mathrm{BU}$ in the lower two panels).

Flours containing $0.8 \%$ of added $\beta$-glucan (bringing the total concentration to $2 \%$ ) were similar to the control regarding

\section{Oat gluten-containing system}

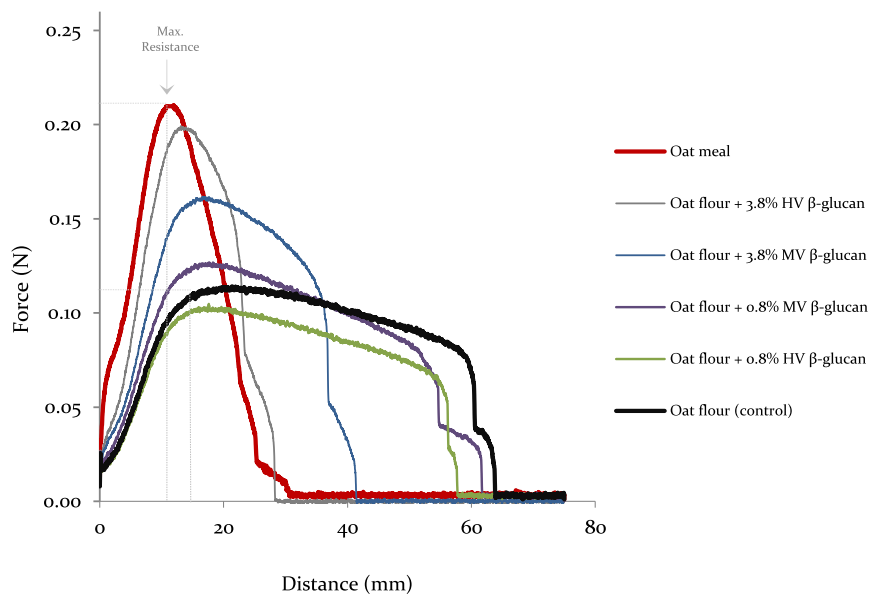

Fig. 2. Effect of adding medium- and high-viscosity $\beta$-glucan on extensibility properties of a gluten-containing oat-based dough system. Measurements were performed at $850 \pm 20 \mathrm{BU}$ consistency. The effect of using oat meal (5\% $\beta$-glucan) was the same as using oat flour plus $3.8 \%$ high viscosity $\beta$-glucan. Sieved oat meal was used as a control. 


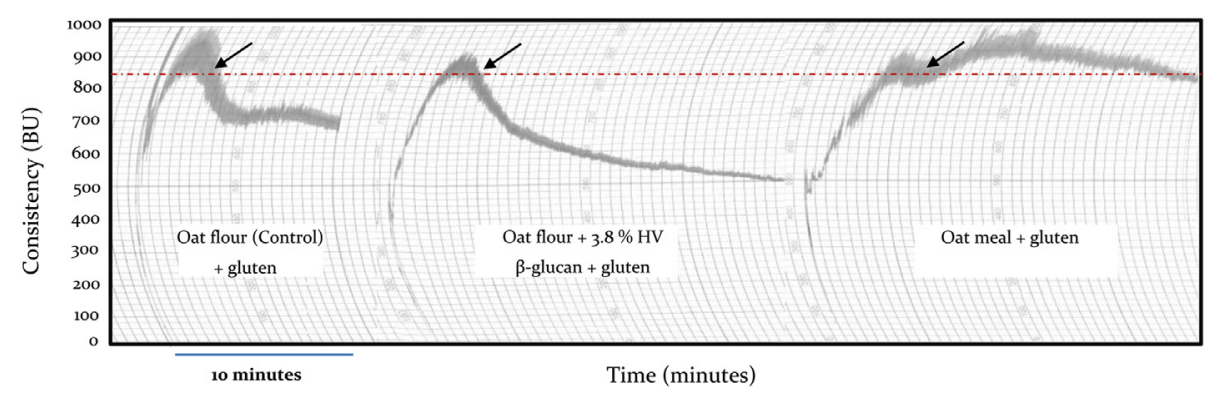

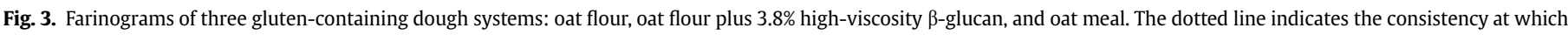
the dough were prepared. The arrows indicate the moment when mixing was stopped. All the dough were very sensitive to over-mixing.

maximum resistance to extension (force). Apparently, a viscosity increasing effect was prevented by adding more water during dough mixing (required to reach the same consistency). However, the extensibility at maximum resistance $(\mathrm{mm})$ and total extensibility ( $\mathrm{mm}$ ) were reduced (Fig. 2). In contrast, in flours that received $3.8 \% \beta$-glucan extra (bringing the total concentration to $5 \%$ ) the resistance to extension increased from 12 to $20 \mathrm{~N}$ in the case of high-viscosity $\beta$-glucan, and from 12 to $16 \mathrm{~N}$ for medium-viscosity $\beta$-glucan (Fig. 2). In this case, adding water to achieve the standard consistency did not prevent an increase in stiffness. Extensibility at maximum resistance and total extensibility were also significantly reduced (Fig. 2). There was no significant difference between oat meal and the flour containing 3.8\% of added high-viscosity $\beta$-glucan in the gluten-containing system (Fig. 2). Oat meal and flours with higher $\beta$-glucan content required more water and a longer time to reach the $850 \pm 20 \mathrm{BU}$ consistency (Fig. 3). High and mediumviscosity $\beta$-glucan had the same water binding capacity. All results are summarised in Table 2 .

\subsection{Effect of oat $\beta$-glucan in a gluten-free oat-based dough system}

In the absence of gluten, addition of $3.8 \% \beta$-glucan to oat flour caused an increase of $73 \%$ in dough maximum resistance to extension (force) and a reduction of $\sim 20 \%$ of extensibility at maximum resistance and total extensibility $(\mathrm{mm})$; there was no significant difference between flours containing high or mediumviscosity $\beta$-glucan and oat meal (Fig. 4A).

Glucanase treatment of the dough containing an extra $3.8 \%$ high-viscosity $\beta$-glucan, reversed the viscosity effect of added $\beta$ glucan. The dough had the same maximum resistance to extension (force) as the control, but lower total extensibility (mm) (Fig. 4B).

In the Farinograph the control dough had a peak time of 2 min. Addition of $\beta$-glucan increased the peak time (Fig. 5). The flour containing high-viscosity $\beta$-glucan and oat meal needed about $10 \mathrm{~min}$ to reach stable consistency (Fig. 5). The effect of the enzymes was also observed in the farinogram as a reduction of the width of the oscillations and a reduction in the time needed to reach the stable consistency (Fig. 5). Flours with higher $\beta$-glucan content did require more water to reach the desired peak consistency of $900 \mathrm{BU}$.

\subsection{Effect of oat $\beta$-glucan on gas retention capacity}

The effect of $\beta$-glucan on gas retention capacity was tested by comparing the specific volumes of oat flour and oat meal in the gluten-containing and the gluten-free system. In both systems, the specific volumes ranged between 1.19 and $1.31 \mathrm{~mL} / \mathrm{g}$. However, a small but significant difference between the specific volume gain of the dough after proofing was observed. In both systems, the dough made of oat flour gained 3\% more specific volume than the oat meal dough (Table 2).

The specific volume gain in the gluten-containing system was $6 \%$ larger than in the gluten-free system for both oat flour and oat meal (Table 2). However, this result cannot be only attributed to the presence of gluten, because the dough consistency was also different. The appearance of the dough after proofing was also different in both systems: oat flour dough did not expand uniformly but more to the sides, with pores on the surface, while oat meal dough had a firm and rounded shape.

\section{Discussion}

Application of oats in bread-like products is restricted due to problems in dough handling and a loss of product quality (Flander et al., 2007). In this study we have determined the effects of oat $\beta$ glucan content and viscosity/molecular weight on the extensibility

Table 2

Summary of results of extensibility and gas retention capacity tests.

\begin{tabular}{|c|c|c|c|c|c|c|c|c|c|}
\hline System & Flour type & $\begin{array}{l}\text { Farinograph } \\
\text { consistency }^{\mathrm{a}}(\mathrm{BU})\end{array}$ & $\begin{array}{l}\text { Water } \\
\text { added }(\mathrm{mL})\end{array}$ & $\begin{array}{l}\text { Resistance to } \\
\text { extension }(\mathrm{N})\end{array}$ & $\begin{array}{l}\text { Mixing } \\
\text { time (min) }\end{array}$ & $\begin{array}{l}\text { Extensibility at max. } \\
\text { Resistance }(\mathrm{mm})\end{array}$ & $\begin{array}{l}\text { Extensibility } \\
\text { total }(\mathrm{mm})\end{array}$ & $\begin{array}{l}\text { Specific } \\
\text { volume }^{\mathrm{b}}(\mathrm{mL} / \mathrm{g})\end{array}$ & $\begin{array}{l}\text { Specific vol. } \\
\text { gain }^{\mathrm{C}} \%\end{array}$ \\
\hline \multirow{6}{*}{$\begin{array}{l}\text { With } \\
\text { gluten }\end{array}$} & Oat flour (control) & 850 & 6.2 & $0.12 \pm 0.08$ & 2.0 & $21.0 \pm 1.6$ & $61.0 \pm 7.4$ & $1.29 \pm 0.07$ & $51 \pm 0.09$ \\
\hline & Oat flour $+0.8 \% \mathrm{MV}$ & 850 & 6.6 & $0.12 \pm 0.05$ & 2.0 & $18.2 \pm 1.3$ & $56.7 \pm 6.2$ & - & - \\
\hline & Oat flour $+0.8 \% \mathrm{HV}$ & 850 & 6.6 & $0.10 \pm 0.06$ & 2.0 & $17.1 \pm 0.8$ & $55.9 \pm 4.8$ & - & - \\
\hline & Oat flour $+3.8 \% \mathrm{MV}$ & 850 & 7.8 & $0.16 \pm 0.07$ & 2.0 & $16.0 \pm 0.8$ & $38.2 \pm 2.2$ & - & - \\
\hline & Oat flour $+3.8 \% \mathrm{HV}$ & 850 & 7.8 & $0.20 \pm 0.01$ & 3.0 & $13.5 \pm 1.0$ & $26.1 \pm 2.6$ & - & - \\
\hline & Oat meal & 850 & 6.7 & $0.20 \pm 0.01$ & 5.0 & $10.9 \pm 1.1$ & $26.0 \pm 3.4$ & $1.31 \pm 0.10$ & $48 \pm 0.10$ \\
\hline \multirow[t]{5}{*}{ Gluten-free } & Oat flour (control) & 650 & 4.4 & $0.12 \pm 0.09$ & 2.5 & $7.9 \pm 0.5$ & $15.0 \pm 2.4$ & $1.26 \pm 0.8$ & $45 \pm 0.14$ \\
\hline & Oat flour $+3.8 \% \mathrm{MV}$ & 650 & 5.4 & $0.22 \pm 0.13$ & 4.0 & $6.3 \pm 0.6$ & $12.4 \pm 1.2$ & - & - \\
\hline & Oat flour $+3.8 \% \mathrm{HV}$ & 650 & 5.4 & $0.22 \pm 0.14$ & 10.0 & $5.8 \pm 0.6$ & $11.2 \pm 1.5$ & - & - \\
\hline & $\begin{array}{l}\text { Flour }+3.8 \% \text { HV (treated } \\
\text { with Glucanase) }\end{array}$ & 650 & 5.5 & $0.13 \pm 0.2$ & 6.0 & $6.0 \pm 0.9$ & $11.0 \pm 1.3$ & - & - \\
\hline & Oat meal & 650 & 5.7 & $0.18 \pm 0.18$ & 10.0 & $7.5 \pm 0.9$ & $12.2 \pm 1.0$ & $1.19 \pm 0.02$ & $42 \pm 0.09$ \\
\hline
\end{tabular}

\footnotetext{
a Consistency $\pm 20 \mathrm{BU}$.

b Measured at $20 \mathrm{~mL}$ total gas production, average of 5 samples.

c Specific vol. gain $=\frac{\text { specific vol. after proofing-specific vol. after mixing }}{\text { Specifc vol. after mixing }}$.
} 

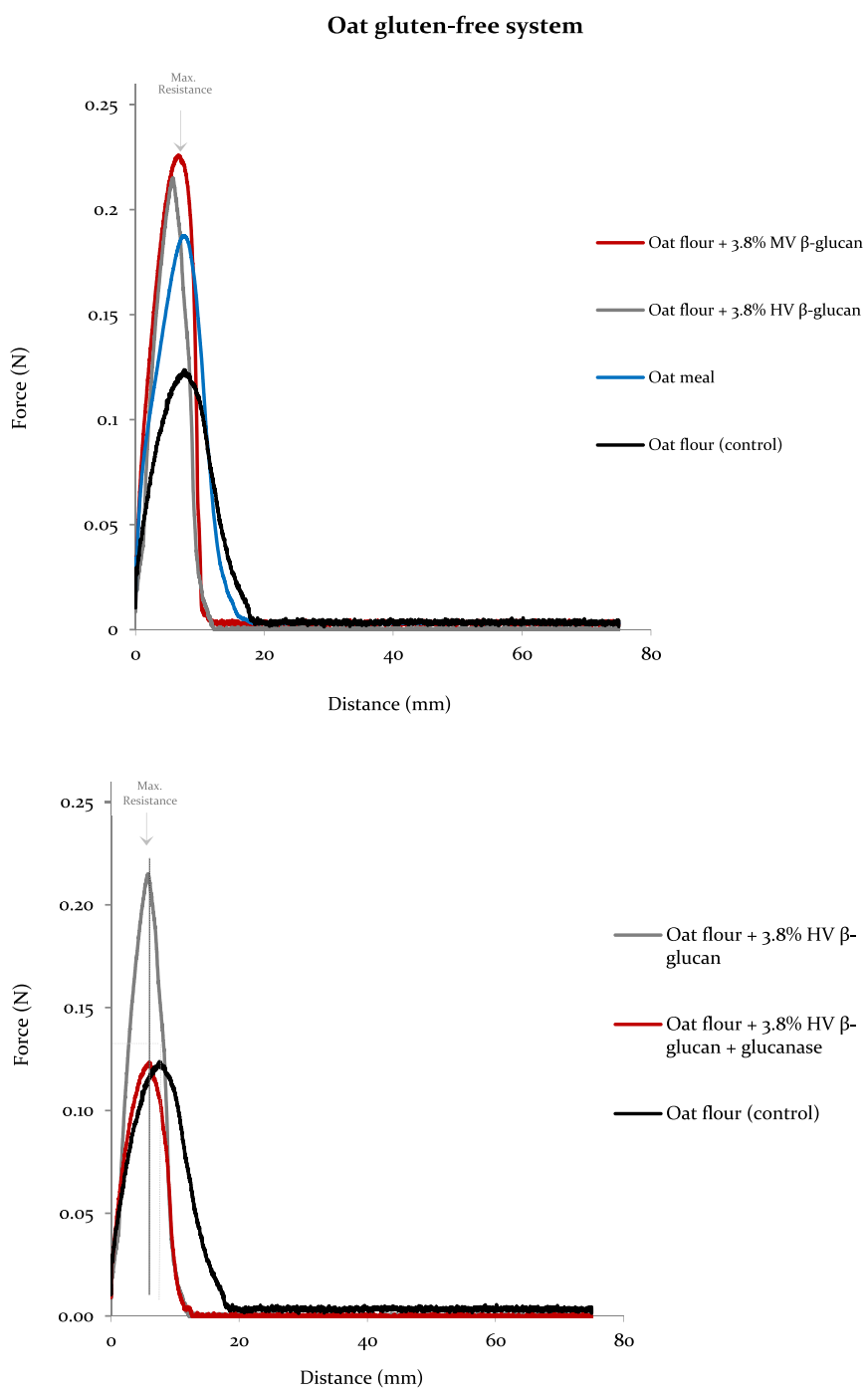

Fig. 4. Effect of $\beta$-glucan on extensibility properties of a gluten-free oat-based system. Top panel. Effect of medium- and high-viscosity $\beta$-glucan. Bottom panel. Effect of glucanase treatment. The effect on $\beta$-glucan was reversed after treating the oat flour with an additional 3.8\% $\beta$-glucan with endo- and exo-glucanase (Megazyme). The treatment resulted in a loss of the extensibility observed in the control. All measurements were performed at $650 \pm 20$ BU consistency.

properties of an oat dough. To confirm the functionality of $\beta$-glucan we either added high- or medium-viscosity $\beta$-glucan, or used a glucanase to remove (part of) such effect.

In order to create a point of reference, we decided to perform our experiments at the same consistency. This required adjusting the amount of water added and the mixing time, as flours with higher $\beta$-glucan content needed more water to reach the same consistency than flours with low $\beta$-glucan content. This behaviour is comparable to that observed by Wang et al. (2002) in glutencontaining flours that received additions of water-extractable pentosans. Suprisingly, the high-viscosity $\beta$-glucan used in this study required the same amount of water as the medium-viscosity type to reach the desired Farinograph consistency. We had expected high viscosity $\beta$-glucan to absorb more water as the solubility and viscosity of polysaccharides are controlled partly by molecular weight (Wood, 2011), but as we added the $\beta$-glucan on a weight/weight basis, the molecular weight of the $\beta$-glucan apparently does not affect the total water binding capacity per unit of mass. It may affect the time required for hydration, as high molecular weight $\beta$-glucan required more time to fully absorb the same amount of water (Table 1). In contrast, in the gluten-free as well as the gluten-containing system, the effect of $\beta$-glucan on dough extensibility properties was related to both concentration and molecular weight (viscosity). This result is in accordance with the results reported by Skendi et al. (2009), who studied by creeprecovery measurements the effect of barley $\beta$-glucan extracts on dough rheology of a poor and good bread-making quality wheat flour. They found that the rheological behaviour of flours enriched with barley $\beta$-glucan depended on concentration and on molecular weight, but also on the type of flour used; barley $\beta$-glucan-enriched wheat flours were stiffer and more resistant to deformation (Skendi et al., 2009). Increasing the concentration of oat $\beta$-glucan in oat flour increased dough resistance to extension (stiffness) and reduced dough extensibility, with high-viscosity $\beta$-glucan having a larger impact. However, the associated reduction of dough extensibility not necessarily would result in a lower volume but in a coarser dough and crumb structure (Kloek et al., 2001). If dough extensibility is a measure of dough elasticity, an increase would mean a higher stability of small gas cells that are mixed in and act as growth nuclei. The more nuclei, the better (finer) the crumb structure (Kloek et al., 2001).

Bran particles can also affect dough properties (Noort et al., 2010). Previous studies indicated that when wheat flour is mixed with oat flour to enrich the fibre content of wheat bread, this resulted in loaves with a reduced specific volume (Flander et al., 2007; Noort et al., 2010; Popa et al., 2012; Tiwari et al., 2013), indicating that the gluten network was disrupted. This disruption was attributed to the bran particles present in oat meal and to its high content of $\beta$-glucan. We compared commercially available oat meal and sieved oat flour. The concentration of $\beta$-glucan was significantly higher in the oat meal ( $5 \%$ versus $1.2 \%$ ), indicating that the bran fraction of the meal contains a higher concentration of $\beta$ glucan. Dough of the sieved oat flour had a higher extensibility than oat meal. When $\beta$-glucan was added to the flour up to $5 \%$, the extensibility decreased to the level of oat meal. This means that the $\beta$-glucan content is sufficient for this effect, as we observed no additional effect of bran particles on extensibility. So the increase in dough stiffness, the loss of extensibility and the lower specific volume gain observed in oat meal dough can be attributed to its high content of $\beta$-glucan (5\%). Similarly, Skendi et al. (2009) observed that $\beta$-glucan from barley can affect wheat dough rheology already at very low concentrations: additions of $1.0 \%(\mathrm{w} /$ w) produced a hampering effect on the rheology of good quality wheat flour, while an improving effect was observed in weak wheat flour. In our case, increasing the concentration of $\beta$-glucan in oat flour from $1.2 \%$ to $2 \%$ did not interfere with the formation of the gluten network in the gluten-containing system.

The effect of $\beta$-glucan on extensibility properties of gluten might be comparable to the effect of water-extractable pentosans, which are also polysaccharides that can interfere with the formation of the gluten network (Wang et al., 2004a). Three mechanisms have been proposed to explain this phenomenon: disturbed viscosity, depletion of molecular attraction between gluten molecules, and modification of Van der Waals forces between particles (Wang et al., 2004a, 2004b). As $\beta$-glucan has a great affinity to bind water (Ahmad et al., 2010), competition with gluten and other waterbinding components can occur in the system, and this would interfere with the development of the gluten network (Wang et al., 2002). This may explain why we were not able to obtain a dough at a consistency of $650 \pm 20 \mathrm{BU}$ in the gluten-free system.

The treatment with glucanase completely reversed the stiffness of the dough induced by addition of $3.8 \%$ high-viscosity $\beta$-glucan. Interestingly, the glucanase-treated flour had a lower extensibility than the control. This can be explained by the intrinsic $\beta$-glucan of 


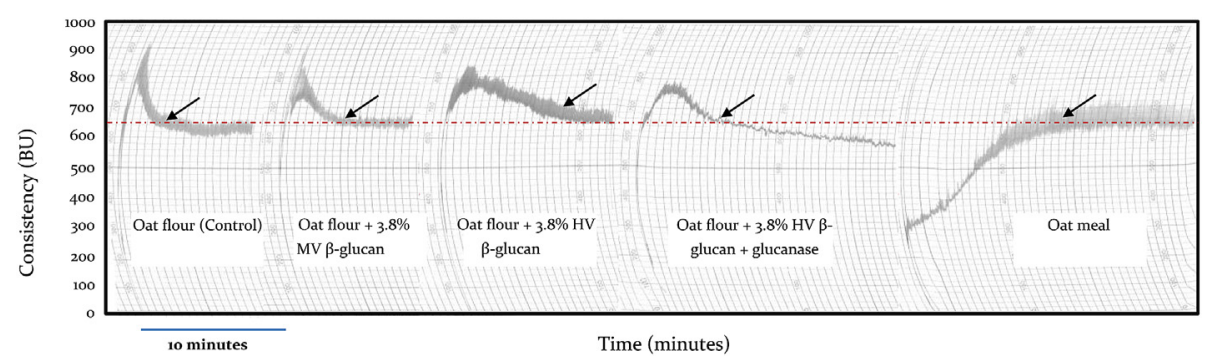

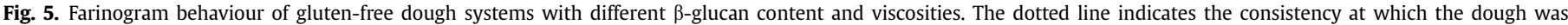
prepared. The arrows indicate the moment when mixing was stopped. HV = high-viscosity.

the oat flour used as a control - that were also degraded by the enzyme -, being responsible for conferring the extensibility that oat flour accounted for. This supports the results of Lazaridou et al. (2007), who reported $\beta$-glucan as improving the viscoelastic properties of gluten-free flours when added in concentrations from 1 to $2 \% \mathrm{w} / \mathrm{w}$. Higher concentrations had a negative impact and decreased loaf specific volume (Pastuszka et al., 2012). Our findings confirm that $\beta$-glucan is relevant for the rheology of oat dough.

Low $\beta$-glucan flour produced a dough with better extensibility properties and gas retention capacity. It is therefore necessary to find the optimum balance between content and composition to obtain the best bread quality, and this might be done by selecting oat varieties with low $\beta$-glucan content of low viscosity and molecular weight, and by a correct adjustment of the water in the formulation. In addition, fermentation may reduce the level of $\beta$ glucan. Sour-dough preserved viscosity of oat bran $\beta$-glucan in a wheat-based dough better than yeast fermentation did (Gamel et al., 2015).

Reducing $\beta$-glucan content and viscosity may compromise the health benefits. According to literature, the magnitude of the physiological effect that leads to a lowering of blood glucose level in humans is dependent on $\beta$-glucan viscosity: the higher the viscosity, the larger the glucose reduction (Mälkki, 2004; Wood, 2007). The relation between the viscosity type of $\beta$-glucan and cholesterol reduction has not yet been demonstrated (Wood, 2007). As a consequence the optimum balance between health benefits and technological quality of the end product with regard to $\beta$ glucan concentration remains to be determined. In addition, it is important to consider that a high internal water content may also be negative for shelf life properties, which are another major drawback of GF bread.

\section{Conclusions}

The behaviour of $\beta$-glucan in dough systems is governed by two factors: concentration and molecular weight (viscosity), provided that the appropriate amount of water is added. Low $\beta$-glucan oat flour has better extensibility properties than oat meal dough or oat flour dough enriched with $\beta$-glucan. Overall, our findings indicate that oat $\beta$-glucan is a key component determining rheology of oatbased dough systems. At least up to $2 \% \beta$-glucan appears to be positive for baking quality. Whether it is possible to make a good dough of oat containing significantly more $\beta$-glucan remains to be determined.

\section{Acknowledgements}

This research was funded by the Celiac Disease Consortium, an Innovative Cluster approved by the Netherlands Genomics Initiative and partially funded by the Dutch Government (BSIK03009) and by the Netherlands' Ministry of Economic Affairs (KB05-001019, KB05-003-032, KB15-001-003 and KB15-001-007).

\section{References}

Ahmad, A., Anjum, F.M., Zahoor, T., Nawaz, H., Ahmed, Z., 2010. Extraction and characterization of $\beta$-d-glucan from oat for industrial utilization. Int. J. Biol. Macromol. 46, 304-309.

Anderson, J.W., Chen, W., 1986. Cholesterol-lowering properties of oat products. In: Webster, F.H. (Ed.), Oats, Chemistry and Technology. AACC International, Inc. USA, pp. 303-309.

Bell, S., Goldman, V.M., Bistrian, B.R., Arnold, A.H., Ostroff, G., Forse, R.A., 1999. Effect of $\beta$-glucan from oats and yeast on Serum Lipids. Crit. Rev. Food Sci. Nutr. 39, 189-202.

Butt, M.S., Tahir-Nadeem, M., Khan, M.K.I., Shabir, R., Butt, M.S., 2008. Oat: unique among the cereals. Eur. J. Nutr. 47, 68-79.

Colleoni-Sirghie, M., Kovalenko, I.V., Briggs, J.L., Fulton, B., White, P.J., 2003. Rheological and molecular properties of water soluble $(1,3)(1,4)-\beta$-d-glucans from high- $\beta$-glucan and traditional oat lines. Carbohydr. Polym. 52, 439-447.

EFSA, 2010. Scientific opinion on the substantiation of a health claim related to oat $\beta$-glucan and lowering blood cholesterol and reduced risk of (coronary) heart disease pursuant to Article 14 of regulation (EC) No 1924/2006. EFSA J. 8 (12), 1885.

FDA, 1997. Food labelling: health claims; oat coronary heart disease. Fed. Regist. 62, 3583-3601.

Flander, L., Salmenkallio-Marttila, M., Suortti, T., Autio, K., 2007. Optimization of ingredients and baking process for improved wholemeal oat bread quality. LWT Food Sci. Technol. 40, 860-870.

Gamel, T.H., Abdel-Aal, E.-S.M., Tosh, S.M., 2015. Effect of yeast-fermented and sourdough making processes on physicochemical characteristics of $\beta$-glucan in whole wheat/oat bread. LWT Food Sci. Technol. 60, 78-85.

Hüttner, E.K., Bello, F.D., Arendt, E.K., 2010. Rheological properties and bread making performance of commercial wholegrain oat flours. J. Cereal Sci. 52 $65-71$.

Hüttner, E.K., Bello, F.D., Zannini, E., Titze, J., Beuch, S., Arendt, E.K., 2011. Physicochemical properties of oat varieties and their potential for bread making. Cereal Chem. J. 88, 602-608.

Kloek, W., van Vliet, T., Meinders, M., 2001. Effect of bulk and interfacial rheological properties on bubble dissolution. J. Colloid Interface Sci. 237, 158-166.

Lazaridou, A., Biliaderis, C.G., 2007. Molecular aspects of cereal $\beta$-glucan functionality: physical properties, technological applications and physiological effects. J. Cereal Sci. 46, 101-118.

Lazaridou, A., Duta, D., Papageorgiou, M., Belc, N., Biliaderis, C.G., 2007. Effects of hydrocolloids on dough rheology and bread quality parameters in gluten-free formulations. J. Food Eng. 79, 1033-1047.

Londono, D.M., Smulders, M.J.M., Visser, R.G.F., Gilissen, L.J.W.J., Hamer, R.J., 2014. Development of a standard test for dough-making properties of oat cultivars. J. Cereal Sci. 59, 56-61.

Londono, D.M., Van 't Westende, W.P.C., Goryunova, S.V., Salentijn, E.M.J., Van den Broeck, H.C., Van der Meer, I.M., Gilissen, L.J.W.J., Smulders, M.J.M., 2013. Avenin diversity analysis of the genus Avena (oat). Relevance for people with celiac disease. J. Cereal Sci. 58, 170-177.

Mälkki, Y., 2004. Trends in dietary fibre research and development. Acta Aliment. 33, 39-62.

Mathews, R., 2011. Current and potential health claims for oat products. In: Webster, F., Wood, P. (Eds.), Oats: Chemistry and Technology, pp. 275-300.

Noort, M.W.J., van Haaster, D., Hemery, Y., Schols, H.A., Hamer, R.J., 2010. The effect of particle size of wheat bran fractions on bread quality - Evidence for fibre-protein interactions. J. Cereal Sci. 52, 59-64.

Othman, R.A., Moghadasian, M.H., Jones, P.J.H., 2011. Cholesterol-lowering effects of oat $\beta$-glucan. Nutr. Rev. 69, 299-309.

Pastuszka, D., Gambuś, H., Ziobro, R., Buksa, K., Sabat, R., Augustyn, G., 2012. Impact of oats B-glucans on properties of gluten-free bread. J. Microbiol. Biotechnol. Food Sci. 1, 972-979. 
Peighambardoust, S.H., Fallah, E., Hamer, R.J., Van der Goot, A.J., 2010. Aeration of bread dough influenced by different way of processing. J. Cereal Sci. 51, 89-95.

Popa, A., Duță, D., Niculiță, P., 2012. Recent advances in oat-based functional cereal products. Rom. Biotechnol. Lett. 17, 7717-7725.

Pulido, O., Gillespie, Z., Zarkadas, M., Dubois, S., Vavasour, E., Rashid, M., Switzer, C., Godefroy, B.S., 2009. Introduction of oats in the diet of individuals with celiac disease: a systematic review. Adv. Food Nutr. Res. 57, 235-285.

Skendi, A., Papageorgiou, M., Biliaderis, C.G., 2009. Effect of barley $\beta$-glucan molecular size and level on wheat dough rheological properties. J. Food Eng. 91, 594-601.

Tiwari, U., Cummins, E., Brunton, N., O'Donnell, C., Gallagher, E., 2013. A comparison of oat flour and oat bran-based bread formulations. Br. Food J. 115, 300-313.
Thompson, T., 2000. Folate, iron, and dietary fiber contents of the gluten-free diet. J. Am. Diet. Assoc. 100, 1389-1396.

Wang, M., van Vliet, T., Hamer, R.J., 2004a. How gluten properties are affected by pentosans. J. Cereal Sci. 39, 395-402.

Wang, M.W., Van Vliet, T., Hamer, R.J., 2004b. Evidence that pentosans and xylanase affect the re-agglomeration of the gluten network. J. Cereal Sci. 39, 341-349.

Wang, M., Hamer, R.J., van Vliet, T., Oudgenoeg, G., 2002. Interaction of water extractable pentosans with gluten protein: effect on dough properties and gluten quality. J. Cereal Sci. 36, 25-37.

Wood, P.J., 2007. Cereal $\beta$-glucans in diet and health. J. Cereal Sci. 46, 230-238.

Wood, P.J., 2011. Oat $\beta$-glucan: properties and function. In: Webster, F., Wood, P. (Eds.), Oats: Chemistry and Technology, pp. 219-254. 